\title{
As conquistas da Educação do Campo e o avanço da extrema-direita: desafios e perspectivas
}

\section{The achievements of countryside education and the advance of the far-right: challenges and perspectives}

Maria de Fátima Almeida Martins Doutora em Geografia, Professora Titular da UFMG, Brasil falmartins.ufmg@gmail.com

Abigail Bruna da Cruz Geógrafa, Mestranda em Geografia pela Universidade Federal de Alfenas, Brasil Bolsista CAPES abigail.cruz@sou.unifal-mg.edu.br

Leonardo Lencioni Mattos Santos Geógrafo, Mestrando em Geografia pela Universidade Federal de Alfenas, Brasil Bolsista CAPES leonardo.lencioni@sou.unifal-mg.edu.br

Jefferson Nunes Geógrafo, Mestrando em Geografia pela Universidade Federal de Alfenas, Brasil jefferson.nunes@sou.unifal-mg.edu.br

\section{Resumo}

A pressão dos movimentos socioterritoriais de luta pela terra, em articulação com diferentes instituições da sociedade civil organizada e, associada a isso, um governo de esquerda, que assumiu a educação para as escolas do campo como política pública, contribuíram para o fortalecimento da Educação do Campo. Neste compromisso coletivo, o objetivo foi garantir a criação e manutenção das escolas em espaços rurais com uma proposta pedagógica vinculada à sua realidade, investir na formação de professores voltados para atender essas escolas rurais e a elaboração de materiais didáticos destinados a essa população. Essas ações foram garantidas por políticas públicas constituídas por dentro do Programa Nacional de Educação do Campo (PRONACAMPO), sendo uma dessas políticas o Programa Nacional do Livro Didático do Campo (PNLD Campo). Mas, com o fortalecimento da extrema-direita e da bancada ruralista na política brasileira desde 2016, está em curso um ataque às políticas voltadas ao campo, resultando em fechamento e até mesmo a destruição de algumas escolas rurais, corte de verbas na política de formação de professores para o campo, o encerramento do PNLD Campo e a desarticulação do Programa Nacional de Educação na Reforma Agrária (PRONERA). Esse contexto favorece o fortalecimento do movimento organizado por setores do agronegócio, com objetivo de controlar a educação no espaço agrário brasileiro. Neste sentido, discute-se nesse trabalho um breve histórico da Educação do Campo e das políticas públicas educacionais voltadas ao meio rural. Aponta-se algumas das disputas atuais que abarcam a educação do/no campo, bem como a relação dessas disputas com o aumento do poder das elites agrárias a partir de 2016, demonstrando como a concentração fundiária está na base desses processos.

Palavras-chave: Educação do Campo; Política Pública; Agricultura Familiar; Campesinato; Agronegócio; Neoliberalismo na educação. 


\begin{abstract}
The pressure of socio-territorial movements of struggle for land, in articulation with different institutions of organized civil society and, associated with that, who assumed education for countryside schools as public policy contributed to the strengthening of Countryside Education. In this collective commitment, the objective was to guarantee the creation and maintenance of schools in rural spaces with a pedagogical proposal linked to their reality, to invest in the training of teachers to serve these rural schools and prepare teaching materials for this population. These actions were guaranteed by public policies established within the National Countryside Education Program (PRONACAMPO). One of these policies was the National Field Textbook Program (PNLD-Campo). This context favours strengthening the movement organized by agribusiness sectors to control education in the Brazilian agrarian space. In this sense, this paper discusses a brief history of Rural Education and public educational policies aimed at the field. Furthermore, it points out some of the current disputes that encompass the education of the/in the field and the relationship of these disputes with the increase in the power of the agrarian elites from 2016, demonstrating how land concentration is in the basis of these processes. Finally, we point how urgent is an articulation to confront the neoliberal advance on State and Rural Education.
\end{abstract}

Keywords: Rural education; Public Policy; Family Agriculture; Peasantry; Agribusiness; Neoliberalism in Education.

\title{
1. INTRODUÇÃO
}

A construção desse artigo se deu a partir dos debates realizados na Mesa Redonda "As conquistas da Educação do Campo e o avanço da extrema direita: Desafios e perspectivas", realizada no II Colóquios Geográficos do Programa de Pós-Graduação em Geografia da UNIFAL-MG no dia 30/07/2021. A realização dessa mesa visou fomentar o debate sobre o estado teórico-prático do movimento da Educação do Campo, além de compreender quais foram os avanços garantidos pelos agentes desse movimento para a educação dos sujeitos do campo e quais são os atuais desafios impostos pelo avanço desenfreado das políticas de extrema-direita sob essa modalidade de ensino. Para alcançar esse objetivo foi realizado um levantamento e análise de material bibliográfico, análise documental das normativas sobre a Educação do Campo, coleta e análise de dados secundários do INEP e FNDE e IBGE, de modo que todos esses procedimentos contribuíram para a compreensão das conquistas e desafios da Educação do Campo em diferentes contextos políticos.

Este artigo está organizado em três momentos, além da presente introdução e das considerações finais. No primeiro momento é abordado como as relações políticas e econômicas consolidaram uma educação rural pautada no ruralismo pedagógico que subordinava o campo e sua população ao urbano e às necessidades da economia. A educação rural foi fragilizada pelo movimento de Educação do Campo que, tendo como protagonistas os movimentos socioterritoriais camponeses, avançaram na construção de uma educação que valorize o campo e seus sujeitos e que contribua para sua permanência na terra. Para ampliar a análise do processo é enfatizada a tríade terra- territórioEstado na formação socioespacial brasileira e como os governos do Partido dos Trabalhadores, ao 
mesmo tempo que contribuíram para o fortalecimento da educação do/no campo, também favoreceram o agronegócio, não realizando mudanças estruturais.

No segundo momento é feita uma análise de como o meio rural brasileiro é inserido no processo político e econômico do país, sendo entendido como um espaço voltado especificamente para a produção, o que vem influenciando diretamente o fechamento das escolas rurais.

Por fim, no terceiro momento a análise se concentra na produção de material didático para as escolas rurais, analisando os objetivos desses materiais. A discussão se aprofunda com o foco no PNLD Campo e no avanço de movimentos de extrema direita no controle do conteúdo dos materiais didático.

As conquistas da Educação do Campo estão sendo cada vez mais ameaçadas pelo avanço da direita e extrema-direita, mas o movimento de resistência e de enfretamento se encontram presentes e esse artigo, resultado de uma mesa redonda, é uma dessas formas de resistência.

\section{A CONSTITUIÇÃO DA EDUCAÇÃO DO CAMPO NO BRASIL E O PODER AGRÁRIO}

A Educação do Campo no Brasil tem seu nascedouro nas lutas dos camponeses por terra, condições dignas de trabalho e escolas para seus filhos. É preciso compreender, por qual escola e projeto lutam esses camponeses? Nesse sentido, pensar as bases de uma educação voltada para os sujeitos do campo no Brasil significa, aludir que estas envolvem, primeiro, a luta pela terra como centralidade para a permanência no campo e, segundo, pelo protagonismo dos sujeitos como forma da significação da escolarização como direito.

Para entender esse processo histórico de escolarização dos povos do campo no Brasil, passando desde a escola rural à escola do/no campo é necessário inseri-lo no contexto sob o qual foi e permanece, qual seja, o de um campo estruturalmente sob o domínio do latifúndio/minifúndio. Desde os primórdios da formação social brasileira, o campo esteve assentado em atividades voltadas para a exportação, o que significava o uso de grandes extensões de terras e consequentemente a necessidade de grande quantidade de força de trabalho que, pelo tipo de atividade que realizavam e ainda realizam, essa classe trabalhadora não dependia da escolarização para exercer seu trabalho. Ou seja, de uma atividade humana completamente imersa na dependência e consumo do corpo como força para realização das atividades no trabalho, é o próprio trabalho, como bem ressalta Marx em “ $\mathrm{O}$ Capital", o que é:

Antes de tudo, trabalho é um processo em que participam o homem e a natureza, processo em que o ser humano com sua própria ação impulsiona, regula e controla seu intercâmbio material com a natureza. Defronta-se com a natureza como uma de suas forças. Põe em movimento as forças naturais de seu corpo, braços e pernas, cabeça e mãos, a fim de apropriar-se dos recursos da natureza, imprimindo-lhes forma útil à vida humana. (MARX, 1989, p. 202) 
O registro histórico da produção no campo no Brasil foi acompanhado por transformações tanto nas formas como nas condições de trabalho e foram acompanhadas de violência contra indígenas, camponeses e quilombolas, acarretando muita desigualdade. Certo dizer que, ao longo do tempo, mudanças foram também bastantes significativas na redefinição das formas do uso da força de trabalho no campo, especialmente com a entrada no circuito mercantil para a produção de commodities. O movimento de luta e resistência esteve também presente neste caminho da reconfiguração do uso da terra. Para Paulo Alentejano o que houve foi:

[...] uma reconfiguração da luta pela terra. De um lado, verificamos a resistência dos camponeses, indígenas e quilombolas contra o açambarcamento das terras que ocupam pelas forças do latifúndio/agronegócio. De outro, observamos a luta dos movimentos sociais do campo contra um modelo agrário que concentra riqueza, promove devastação ambiental (desmatamento e contaminação de águas, solos, alimentos e trabalhadores por agrotóxicos) e se reproduz com base na violência e na exploração do trabalho (inclusive com trabalho escravo); e por uma reforma agrária que desconcentre a terra, o poder e a riqueza no campo e promova a produção de alimentos saudáveis a partir da perspectiva agroecológica. (ALENTEJANO, 2020, p. 2)

O que se evidencia diante da presença do capital no campo, em um país como o Brasil, com longa extensão territorial, é que a distribuição de terras não se concretizou da mesma forma, em todas as regiões, ou seja, estas características não estão presentes, da mesma forma, em todo o território nacional, variando a inserção no mercado, a presença de tecnologia e a intensidade da produção de cada região. Neste contexto, o conjunto dos trabalhadores do campo, em qualquer dos espaços regionais, com maior ou menor presença de tecnologias no campo, foi estigmatizado, sendo esta considerada uma população atrasada, aquém das ações dadas pelas tecnologias e, principalmente, por não ser escolarizada. Contudo, a escolarização dessa população é necessária e, para isso, a escola pensada para ela foi pautada inicialmente sob a forma de uma educação universalizada e sob o domínio do patrão, dono das terras, à esta escola e educação chamamos de Educação Rural e seu ruralismo pedagógico.

A educação rural que daí emerge vai ser imersa num campo de disputa, e tem como fundamento a manutenção do processo de dominação e manutenção do status quo. Vale aclarar que neste momento, o movimento de constituição da relação campo cidade se intensifica. Por isso, a disputa neste momento, ocorre no campo da dominação econômica entre rural e urbano, entre agricultura e industrialização. Como campo de disputa, a educação rural, neste momento, vai ser circunscrita à ação de dominação dos proprietários de terras com os seus agregados, ou sobre aqueles trabalhadores rurais temporários que vivem o movimento migratório entre o campo e a cidade, próprio do processo de industrialização. Importante destacar que, mesmo com o processo de modernização no campo a partir da segunda metade do século XX isso não vai significar melhoria das condições de vida, muito menos, de escolarização da população que vive no campo. Até a década de 1980 era esse o cenário no campo brasileiro. 
A educação para os povos do campo é pensada na contraposição da educação rural, e esta é demarcada pela população camponesa e está circunscrita àqueles que vivem da atividade do campo na sua diversidade de uso da terra, assim como dos povos originários e suas identidades. É desse campo diverso que a Educação do Campo emerge. É sob essa base que o Movimento da Educação do Campo surge no final do ano de 1980 para fomentar a criação de uma referência teórica, política e metodológica no que diz respeito à construção de um projeto educacional que possa atender as demandas das populações que residem e trabalham no espaço campesino para se contrapor à educação rural. Na pauta desse movimento está a preocupação em construir um projeto de escola vinculado a um projeto de campo e de sociedade numa perspectiva que coloque o campesinato e os camponeses como sujeitos de direitos, não somente na perspectiva de sua integração à dinâmica social e econômica existentes, mas principalmente, na perspectiva de sua transformação, na direção de condições mais justas e igualitárias para todos.

As bases que potencializaram a Educação do Campo emergem da luta dos coletivos constituídos pelos movimentos socioterritoriais, a sociedade civil organizada e as universidades. Essas ações coletivas mobilizadas são as que vão formar e construir as bases para políticas públicas específicas à garantia do direito à educação dos camponeses como: PRONERA, PROCAMPO, PRONACAMPO, RESIDÊNCIA AGRÁRIA e PNLD-Campo. Para além destas, outras conquistas são importantes como: os marcos legais, as Diretrizes Operacionais, Decretos e Resoluções.

Neste sentido, as bases para uma Educação do Campo nascem do processo social da luta de classes onde são materializadas sob "um conjunto de práticas, princípios e políticas que vêm sendo formuladas desde o fim dos anos 1990 por sujeitos envolvidos na construção de um projeto de escola articulado a um de campo e de sociedade" (MOLINA; ANTUNES-ROCHA; MARTINS, 2019, p. 3). Ao mesmo tempo em que avançam como direito instituído é também instituinte da ampliação do imaginário da sociedade brasileira, dos camponeses como sujeitos de direitos, como portadores e construtores de um projeto de futuro e de sociedade, tirando-os do lugar do "atraso" ao qual haviam sido submetidos historicamente.

Portanto, a Educação do Campo foi e continua sendo constituída a partir das ações e dos debates propostos pela sociedade civil organizada, por setores da academia e, principalmente, pelos movimentos socioterritoriais camponeses. Para que seja possível compreender de maneira aprofundada as características das atuais disputas que envolvem a Educação do Campo e a educação no campo brasileiro, torna-se fundamental buscar compreender a totalidade dos conflitos que se desenrolam no país e seus reflexos no meio rural.

Neste sentido, pontuamos que os conflitos e as disputas que envolvem a educação do/no campo no momento atual estão diretamente relacionadas com as disputas políticas que envolvem a educação e o Estado brasileiro como um todo (MOLINA, 2015; CALDART, 2020; SANTOS, 2020a). 
Portanto, apontamos que a luta dos movimentos socioterritoriais pelo acesso e/ou manutenção de uma educação emancipadora é uma das dimensões da questão agrária atual (SANTOS, 2020b).

Entendemos que essa disputa não é somente pelo modelo educacional ou pela existência de escolas rurais, mas sim pelo próprio campo brasileiro e o modelo de desenvolvimento territorial a ele proposto (FERNANDES, 2004; CALDART, 2015; MOLINA, 2015; PEREIRA; ORIGUÉLA; COCA, 2021). Os apontamentos de Moreira (2018) são de grande valia para a compreensão das origens do poder agrário atual e para pontuarmos como a concentração fundiária condiciona as disputas pelo Estado, pela conformação das políticas públicas e, portanto, pelo modelo educacional brasileiro.

Ao apontar como a formação socioespacial brasileira pode nos permitir analisar as raízes e fontes do poder agrário no Brasil, Moreira (2018) indaga o significado da enorme presença do campo na vida social de um país que é, preponderantemente, urbano-industrial. Essa presença verifica-se tanto no plano econômico, sendo o agronegócio um dos setores que "mais favorece" a balança comercial, quanto no plano político, onde a bancada ruralista (ou Frente Parlamentar da Agropecuária) representa 45\% da Câmara Federal e 33\% do Senado (MOREIRA, 2018).

Nossa formação socioespacial tem como base a reafirmação e a permanência do eixo terraterritório-Estado (MOREIRA, 2018). Esse eixo recria uma lógica onde "o monopólio fundiário que se faz monopólio do território, e que, por lógica, se faz monopólio do Estado: quem monopoliza a terra domina o território e quem domina o território controla e põe a seu serviço o Estado (MOREIRA, 2018, p. 49). Neste sentido, se faz necessário compreender como as contradições gestadas na sociedade e no campo brasileiro a partir dos governos do Partido dos Trabalhadores (PT) acabam por refletir, nos dias de hoje, no avanço da burguesia e do agronegócio sobre o Estado brasileiro, sobre a educação e sobre as políticas públicas que beneficiavam a agricultura camponesa/familiar.

Por um lado, durante os governos petistas, houve um favorecimento indiscutível do campesinato/agricultura familiar e, consequentemente, da Educação do Campo, por meio das políticas públicas formuladas neste contexto (CAMACHO, 2014; MOLINA; FREITAS, 2011). Por outro lado, a manutenção dessas políticas se deu através, entre outros fatores, das divisas geradas pelo aumento das exportações associadas a um "neoextrativismo progressista" (GONÇALVES; MILANEZ; WANDERLEY, 2018), onde o agronegócio desempenhou o papel de ser um dos maiores geradores de divisas. Essa contradição apresentava diversos limites, como fica claro no argumento de Frigotto:

Passados quase sete anos do Governo do ex-metalúrgico Luiz Inácio Lula da Silva, eleito por uma base social herdeira do projeto nacional popular, pode-se afirmar que não houve mudança estrutural do projeto dominante da classe burguesa brasileira. A opção que vem se solidificando é do nacional desenvolvimentismo conservador e que, ao contrário de ruptura com classe dominante e seu projeto societário, governa condicionado por ela. O efetivo avanço nas políticas assistenciais e, em parte, redistributivas, sem mudanças estruturais 
podem tornar-se um ovo de serpente e, uma vez mais, reiterar políticas personalistas, patrimonialistas que alimentam e reiteram o projeto societário dos mais desiguais e violentos do mundo. (FRIGOTTO, 2010, p. 25)

Portanto, ao não quebrar com as estruturas responsáveis pela gestação e manutenção das desigualdades sociais, políticas e econômicas do país, os governos do PT alimentaram as contradições que, posteriormente, levaram ao impeachment da ex-presidenta Dilma Rousseff.

Aqui não visamos crucificar o partido ou imputá-lo de toda a culpa pelo avanço da extremadireita no contexto atual, mas sim apontar como a falta de mudanças estruturais minou o poder popular (sindicatos, movimentos sociais, entre outros) e aprofundou o domínio do agronegócio no campo brasileiro. Analisando o final da ditadura empresarial-militar e a abertura para a democracia, Theotonio dos Santos deixou claro o perigo dessa política conciliatória:

\begin{abstract}
A ausência de uma saída revolucionária e os compromissos para os quais o conjunto da oposição brasileira foi empurrado deixam intactas as forças obscurantistas que governaram a nação de 1964 até pelo menos 1986. Em tal caso, o período de transição iniciado em 1986 pode ser o começo de uma era ainda mais obscura para o Brasil, se não conseguir alterar radicalmente a realidade político-ideológica do país. (SANTOS, 2021, p. 177)
\end{abstract}

Ao não se alterarem as estruturas políticas, ideológicas (vide o papel da mídia hegemônica no golpe de 2016) e econômicas extremamente concentradas, os governos petistas favoreceram a ampliação da hegemonia do poder das burguesias agrárias e urbanas. Com a crise econômica e o fim da "aliança" de classes que permitiu os investimentos sociais dos governos petistas, a burguesia (agrária e urbana) realiza um golpe midiático-jurídico-parlamentar (JINKINGS; DORIA; CLETO, 2016). Neste sentido, tanto a mídia hegemônica, quanto a atuação da operação Lava-Jato (cabe lembrar que o juiz que julgou Lula da Silva se tornou Ministro da Justiça do governo que ajudou a eleger), tiveram papéis fundamentais para a farsa golpista. Destacamos, também, a atuação do imperialismo norte-americano para a concretização deste golpe, com a consequente desestruturação de setores estratégicos da economia brasileira, gerada pela operação Lava-Jato (CAMPOS, 2019; FERNANDES, 2019).

Assim, a partir do ano de 2016, com o governo de Michel Temer, a correlação de forças políticas muda drasticamente, fazendo com que diversas políticas agrárias e sociais que favoreciam o campesinato e a agricultura familiar passassem a ser destruídas e/ou sucateadas (SAUER; LEITE, 2017; MITIDIERO JUNIOR; FELICIANO, 2018; ALENTEJANO, 2018). Como exemplo desse processo temos a atuação de Temer em prol do cancelamento dos repasses para o Programa de Aquisição de Alimentos (PAA) e a extinção do Ministério do Desenvolvimento Agrário, este último responsável, entre outras atribuições, pelas políticas de reforma agrária. Neste sentido, o Estado, as políticas públicas e o modelo de desenvolvimento territorial passaram a favorecer ainda mais o agronegócio, em detrimento dos(as) camponeses(as) e agricultores(as) familiares. 
Portanto, como nossa formação socioespacial é baseada na reafirmação e na permanência do eixo terra-território-Estado, ao não atacar a concentração fundiária, de renda, de tecnologia, os projetos de Reforma Agrária implementados até hoje foram insuficientes na resolução dos problemas estruturais do campo brasileiro (ALENTEJANO, 2020; MITIDIERO JUNIOR; FELICIANO, 2018; FERNANDES, 2013; OLIVEIRA, 2015). Neste momento de crises (econômica, política, ambiental), a tendência observada é o aumento da busca da burguesia pelo controle sobre as terras e sobre o Estado, bem como sobre as políticas públicas com potencial emancipatório para o campesinato/agricultura familiar (SAUER; LEITE, 2017).

\section{LUTA DE CLASSES E AS DISPUTAS PELA EDUCAÇÃO DO/NO CAMPO}

É possível perceber atualmente uma disputa pelo território nacional como totalidade, por meio de ataques a territórios materiais (terras indígenas, áreas de quilombos, áreas de reforma agrária, fronteira agrícola) e, também, a territórios imateriais (código ambiental, políticas de reforma agrária, políticas educacionais, políticas de fortalecimento da agricultura familiar, entre outros). Neste sentido, a disputa atual pelo controle dos territórios, dos processos educacionais e das políticas públicas visa aprofundar o domínio das burguesias agrárias no campo brasileiro (CALDART, 2020; SANTOS, 2020b; PEREIRA; ORIGUÉLA; COCA, 2021).

Há, portanto, uma ofensiva por parte das burguesias agrárias em prol de um modelo educacional que repercuta a visão dessa classe, onde o campo é entendido somente enquanto setor produtivo (CALDART, 2020; MOLINA, 2015). Cabe lembrar que esse modelo educacional está diretamente vinculado ao modelo de desenvolvimento territorial proposto pelo agronegócio. A partir desta perspectiva o campo não é tido enquanto espaço de cultura, de sociabilidade, de religiosidades, de temporalidades diferenciadas. Para o agronegócio e a burguesia agrária o campo é visto enquanto local de produção de mercadorias (FERNANDES, 2008), por isso, o projeto educacional a ele proposto deve ser voltado à formação para o mercado de trabalho, por meio de habilidades e competências, como vem sendo realizado pela Reforma do Ensino Médio e pela Base Nacional Comum Curricular (BNCC) em todo o território nacional, bem como por movimentos conservadores específicos do campo, como o "Mães do Agro".

Enquanto que para o campesinato a Educação do Campo é tida como instrumento e produto da luta pela/na terra (REIS et al., 2019), que possibilita a reprodução de seu território, de sua diversidade cultural, de sua economia e de sua história política (ARROYO, 1999), para o agronegócio ela é vista enquanto possibilidade para “[...] manter as relações desiguais do capitalismo se perpetuando, como o trabalho escravo e os gastos do dinheiro público para atender as demandas do capital [...]" (CAMACHO, 2014, p. 74). 
Isso posto, delimitaremos as diversas disputas pelo território (material e imaterial) da educação do/no campo no contexto atual, ou seja, pela criação ou fechamento das escolas, bem como pela conformação das políticas públicas educacionais e de sua estrutura ideológica. Para isso, separamos as disputas em três eixos principais: i) Política de fechamento das escolas do campo e sua nucleação em escolas urbanas; ii) atuação de empresas/instituições vinculadas ao agronegócio na formulação de materiais didáticos e na criação de cursos de capacitação para docentes da rede pública e particular de ensino e; iii) destruição e/ou inviabilização de políticas públicas voltadas para a educação do/no campo.

O quadro atual dessas disputas é caracterizado por uma ofensiva neoliberal visando a conformação e/ou destruição das políticas educacionais que tendem a favorecer um projeto educacional e societário contra-hegemônico (MOLINA, 2015; CALDART, 2020). Como resultado deste processo observa-se a tendência de fechamento das escolas do campo em todo o território nacional, bem como o processo de nucleação das mesmas em centros urbanos.

Para que essa tendência possa ser verificada, separou-se o mapa representado na figura 1. Este mapa temático foi elaborado com base nos dados extraídos do Censo Escolar, mais especificamente das Sinopses Estatísticas da Educação Básica dos anos de 2010 e 2019, disponíveis no sítio virtual do Instituto Nacional de Estudos e Pesquisas Educacionais Anísio Teixeira (INEP). A elaboração do mapa se baseou no método coroplético, devido à sua capacidade de representar espacialmente valores numéricos de determinados fenômenos, desde que estes valores e sua área geográfica sejam definidos por algum tipo de limite, como os políticos/administrativos, a exemplo das unidades da federação (SAMPAIO, 2019). 


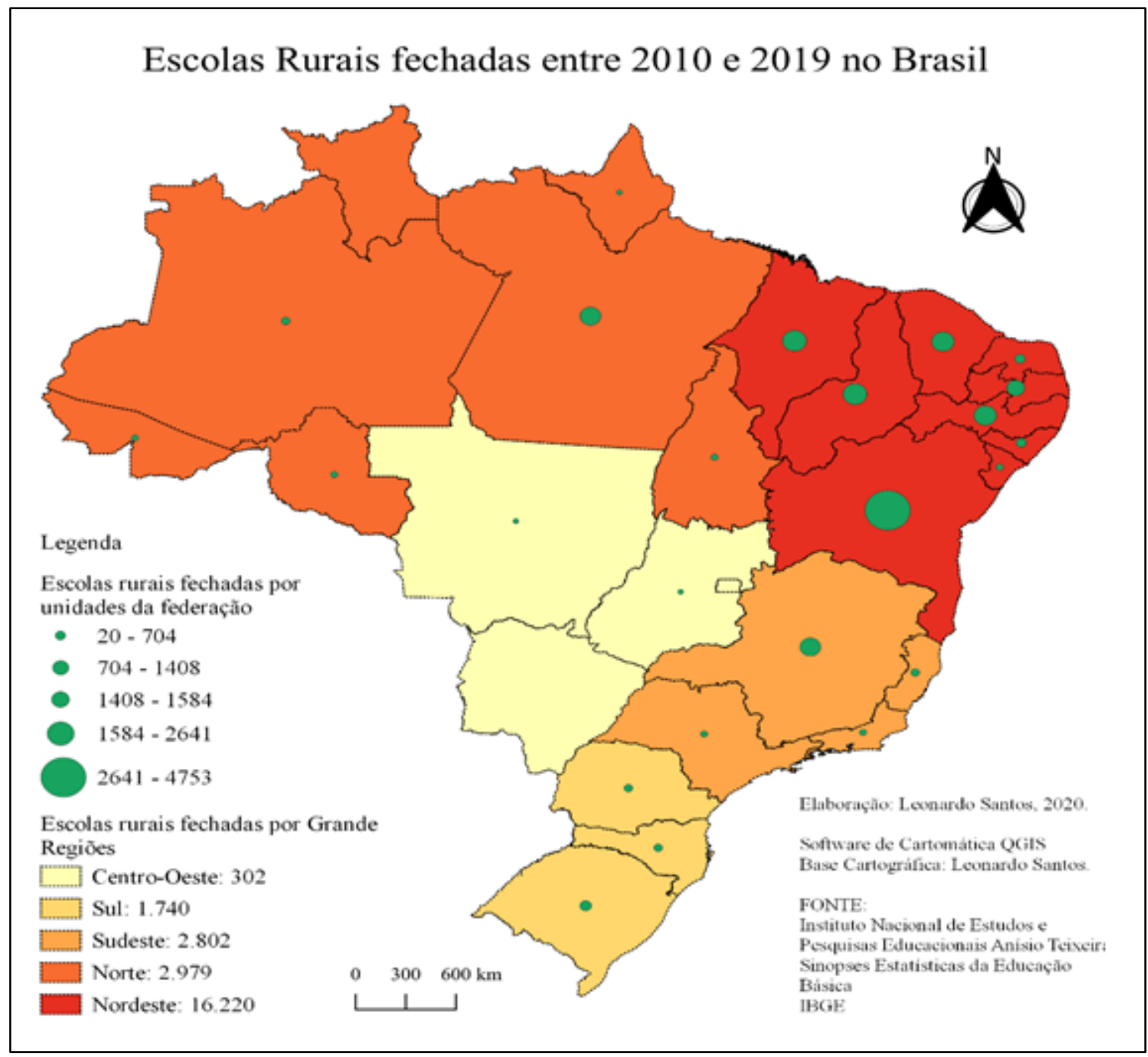

Figura 1 - Espacialização das Escolas Rurais fechadas entre 2010 e 2019 no Brasil.

Fonte: SANTOS, 2020b, p. 49.

O mapa acima representa o fechamento das escolas rurais no Brasil entre os anos de $2010 \mathrm{e}$ 2019, as cores mais claras apontam as Grande Regiões brasileiras com as menores densidades de fechamento - Centro-Oeste, Sul e Sudeste, respectivamente -, enquanto as cores mais escuras apontam as regiões com as maiores densidades de encerramento de escolas, sendo elas Norte e Nordeste. Ademais, optou-se pelo uso dos centróides (ou círculos concêntricos) para possibilitar uma melhor leitura da quantidade de estabelecimentos fechados por unidades da federação, de modo a se demonstrar mais claramente a diferenciação do processo dentro das Grande Regiões. Nesta lógica, quanto maiores os círculos, maior a quantidade de escolas encerradas em uma determinada unidade da federação.

Os dados coletados demonstram que, entre os anos de 2010 a 2019, foram fechadas 24.114 escolas rurais no Brasil. Apenas nos estados de Roraima, Mato Grosso do Sul e Distrito Federal ocorreram acréscimos no número de estabelecimentos educacionais rurais, mesmo que praticamente insignificantes. Ressalta-se que as regiões com o maior número de escolas encerradas são justamente as que apresentam os piores índices de analfabetismo no país. Segundo os dados do IBGE (2015a), 
$11,4 \%$ dos residentes da região Norte e 16,5\% dos residentes da região Nordeste não são alfabetizados; os dados demonstram uma triste superioridade dessas regiões em comparação com as demais regiões do país, onde Centro-Oeste, Sudeste e Sul possuem respectivamente 6,9\%, 5,4\% e $5,3 \%$ de seus residentes não alfabetizados.

Algo que chama a atenção para a perversidade desse processo é que $15 \%$ da população nacional reside no meio rural (IBGE, 2010). A partir dos dados do IBGE (2010; 2015b) foi possível verificar que o número de pessoas que residem em áreas rurais se manteve estável entre 2010 e 2015. Portanto, se entre 2010 e 2015 não houve diminuição do número de habitantes das zonas rurais brasileiras, o encerramento das escolas rurais não deve possuir relações diretas com uma diminuição da demanda por educação. Ao verificarmos as modalidades de ensino que mais foram impactadas por esses fechamentos constatou-se a seguinte tendência (Tabela 1):

Tabela 1: Total de escolas rurais da educação básica em atividade, por modalidade de ensino no Brasil em 2010 e 2019.

\begin{tabular}{ccc}
\hline Modalidade de Ensino & Número de Escolas em 2010 & Número de Escolas em 2019 \\
\hline Educação Infantil & 49.478 & 41.120 \\
Ensino Fundamental - anos iniciais & 72.103 & 47.653 \\
Ensino Fundamental - anos finais & 18.546 & 18.260 \\
Ensino Médio & 2.302 & 3.040 \\
Educação Profissional & 441 & 461 \\
EJA - Ensino Fundamental & 15.273 & 9.523 \\
EJA - Ensino Médio & 482 & 865 \\
Total & 79.388 & 55.345 \\
\hline
\end{tabular}

Fonte: SANTOS, 2020b, p. 53.

Organizado por: Leonardo Santos.

Por meio desses dados é possível observar que as modalidades de ensino que tiveram os maiores impactos a partir do fechamento das escolas rurais foram: 1) Ensino fundamental - anos iniciais, com 24.450 estabelecimentos encerrados; 2) Educação infantil, com 8.358 estabelecimentos encerrados; 3) Educação de Jovens e Adultos (EJA) - Ensino Fundamental, com 5.750 estabelecimentos encerrados e 4) Ensino fundamental - anos finais, com 286 estabelecimentos encerrados. Também é possível observar que os estabelecimentos das modalidades Ensino médio regular e EJA - Ensino Médio obtiveram aumentos de 738 e 383, respectivamente. Já a educação profissional, em 2019, apresentou um acréscimo de 20 estabelecimentos em relação à 2010. Quanto à tabela acima, ressaltamos que certas escolas possuem mais de uma modalidade de ensino, assim, a somatória das modalidades de ensino não irá representar o total de estabelecimentos educacionais existentes.

As tendências apontam para uma grande diminuição no número de estabelecimentos de educação infantil, de ensino fundamental (principalmente os estabelecimentos voltados aos anos iniciais) e de EJA na modalidade ensino fundamental. Desta forma, compreendemos que esse processo poderá engendrar grandes dificuldades para a superação do analfabetismo, principalmente 
o adulto, vide o enorme número de estabelecimentos de EJA encerrados (apesar do aumento no número de estabelecimentos de EJA para ensino médio, o consideramos irrisório frente à escala nacional). Destacamos que esse processo pode agravar ainda mais as altas taxas de analfabetismo no campo brasileiro, haja vista que as modalidades mais impactadas possuem a atribuição, dentre outras, de alfabetizar os(as) educandos(as).

Ainda em relação aos impactos na EJA, contata-se que, no Brasil, o analfabetismo está diretamente relacionado à idade. Para as pessoas de 15 anos ou mais de idade, a taxa de analfabetismo em 2019 era de 6,6\%, frente aos 18\% para as pessoas acima dos 60 anos (IBGE, 2019), isso sem levar em conta a diferenciação entre essa taxa no meio rural e urbano. Como a EJA é responsável, entre outras atribuições, pelo processo de alfabetização de jovens e adultos, o impacto do fechamento de escolas com essa modalidade de ensino pode repercutir negativamente na superação do analfabetismo adulto no campo brasileiro.

Ademais, a distância para as escolas urbanas, os transportes escolares, os horários e as rotinas dos trabalhadores (no caso da EJA) são enormes entraves enfrentados pela população do campo para o prosseguimento de seus estudos no caso de fechamento de escolas em sua comunidade. Diante dessa tendência, Munarim ressalta que:

\begin{abstract}
Entendem esses governantes estaduais e municipais que fechar uma escola no campo e transportar os alunos remanescentes é menos oneroso ao erário público e, de quebra, mais civilizatório ou modernizante, afinal, ainda nessa visão, a escola urbana seria o ideal almejado por todos. Enfim, trata-se do império da racionalidade econômico-financeira e da ideologia do desenvolvimento capitalista urbanocentrado. Por essa perspectiva, não se levam em conta os prejuízos sociais causados com esses procedimentos administrativos de desterritorialização de pessoas e comunidades inteiras. (MUNARIM, 2011, p. 53)
\end{abstract}

Portanto, por meio do discurso acerca da necessidade de racionalização dos custos com a educação do/no campo, passaram a ser elaboradas políticas educacionais estruturadas sobre o tripé meritocracia, avaliação e padronização, gerando uma lógica que fomenta a tanto a evasão escolar, quanto a desterritorialização de camponeses e agricultores familiares (MOLINA, 2015).

Ressalta-se que Caldart (2010) traz outro ponto relevante para a análise das disputas pela Educação do Campo. A autora destaca como motivo para a entrada do agronegócio nesta disputa a busca deste pela formação educacional do agricultor familiar. A realidade abarcada por esse discurso educacional se baseia na necessidade de tornar a agricultura familiar cada vez mais modernizada e integrada ao mercado. Assim, este projeto educacional tem como objetivo "[...] torná-los técnicosprofissionais e integrá-la (agricultura familiar) ao mercado para que sobreviva à competição" (CAMACHO, 2014, p. 346). Desta forma, ao disputarem os territórios educacionais, as instituições vinculadas à agricultura industrial (agronegócio) visam adequar os jovens (camponeses e/ou agricultores familiares) a um processo produtivo vinculado ao agronegócio, sem questioná-lo, ou seja, 
de modo que haja uma subordinação aos seus ditames de forma acrítica (CALDART, 2010; CAMACHO, 2014).

As ações do agronegócio na disputa pelo território imaterial da Educação do Campo englobam cursos de formação para docentes da rede pública em empresas do ramo, projetos coordenados por associações do agronegócio e, também, o financiamento de materiais didáticos por empresas (CAMACHO, 2014; MOLINA, 2015; CALDART, 2010).

Por fim, apontamos para a destruição e/ou inviabilização de políticas públicas voltadas para a educação do/no campo enquanto uma das dimensões dessa disputa. Um dos piores impactos sofridos pela Educação do Campo enquanto política pública se deu por meio da inviabilização do PRONERA a partir de um decreto do presidente da república Jair Bolsonaro. O decreto $\mathrm{N}^{\circ} 10.252$, de 20 de fevereiro de 2020, alterou a estrutura regimental do Instituto Nacional de Colonização e Reforma Agrária (INCRA) e extinguiu a Coordenação-Geral de Educação do Campo e cidadania, sendo esta a responsável pela gestão do PRONERA, inviabilizando-o.

Apesar do PRONERA seguir em funcionamento, observa-se um corte orçamentário que, nos moldes atuais, tende a inviabilizar a amplitude que o programa chegou a ter até o ano de 2016. Em 2008 o orçamento destinado à educação no campo era de 70 milhões de reais, em 2017 o montante diminuiu drasticamente, chegando ao valor de 12 milhões de reais (CANUTO, 2018). Os impactos seguem ocorrendo e as previsões do segundo volume do Projeto de Lei Orçamentária de 2021, para a educação no campo, são de 9 milhões de reais (BRASIL, 2020). Neste sentido, por mais que o programa não tenha sido extinto, a sua aplicação foi amplamente impactada pelos cortes ocorridos no orçamento destinado à sua execução

O programa teve sua origem no descontentamento dos movimentos socioterritoriais a respeito da elevada taxa de analfabetismo e do déficit da oferta educacional no campo (CAMACHO, 2017). Ao longo de sua história, o PRONERA abarcou a Educação de Jovens e Adultos (EJA), o ensino fundamental, o ensino médio, cursos técnicos-profissionalizantes e de ensino superior, chegando até a ter disponibilizado cursos de pós-graduação. O PRONERA se constituiu enquanto uma das maiores e mais amplas políticas públicas educacionais com viés na educação do/no campo. Para se ter noção da importância do PRONERA, entre 1998 e 2010 o programa:

[...] foi responsável pela escolarização e formação de cerca de 400 mil jovens e adultos assentados e/ou acampados da reforma agrária. O Programa capacitou cerca de 300 profissionais egressos dos cursos de ciências agrárias para atuarem na Assessoria Técnica, Social e Ambiental junto aos Projetos de Assentamento de Reforma Agrária e agricultura familiar. (BRASIL, 2011 apud CAMACHO, 2017, p. 16)

A partir desses dados é possível se ter uma ideia do impacto que essa política pública ocasionou para a produção e reprodução dos territórios camponeses em todo o país, bem como para a melhoria das condições de vida desses sujeitos. O programa realizou a maioria de suas ações a partir 
da modalidade EJA fundamental, que apresenta como seu público-alvo pessoas com faixa etária acima dos 15 anos, justamente a parte da população rural que conta com a maior porcentagem de analfabetos (IBGE, 2019).

Além disso, destacamos que o Programa Nacional do Livro Didático-Campo (PNLDCampo) também foi uma política pública extremamente importante conquistada a partir da luta da sociedade civil, da academia e, principalmente, dos movimentos socioterritoriais. Assim como o PRONERA, o PNLD-Campo passou por um processo de desestruturação, as características deste processo e do programa como um todo serão abordados a seguir.

\section{A EDUCAÇÃO DO CAMPO E A CONSTRUÇÃO DE MATERIAIS DIDÁTICOS}

O material didático é um instrumento essencial para o processo de ensino aprendizagem, mas é importante destacar que sua contribuição neste processo depende da relação que o professor tem com esse material, um professor com uma formação adequada e com um material didático de qualidade, são essenciais para o estabelecimento de uma educação emancipadora.

Com relação à formação de professores destaca-se as licenciaturas em Educação do Campo, como desdobramento da política pública, ganhou territorialidade nacional, com presença em todas as regiões brasileiras, alcançando no ano de 2021 uma oferta de 44 Cursos desta modalidade, em 29 Universidades e 5 Institutos Federais. Importante também ressaltar a existência de cursos superiores em diferentes áreas de conhecimento, com oferta de turmas específicas para os assentados da Reforma Agrária, através do PRONERA (Pedagogia; História; Artes; Direito, Agronomia, Enfermagem, Serviço Social, Administração, dentre outros).

Dentre as políticas de fortalecimento da Educação do Campo, as licenciaturas representam uma ocupação fundante na formação de educadores para escolas do campo. Estas assumem como

[...] matriz original dessa política de formação docente tem como horizonte formativo o cultivo de uma nova sociabilidade, cujo fundamento seja a superação da forma capitalista de organização do trabalho, na perspectiva da associação livre dos trabalhadores, na solidariedade e na justa distribuição social da riqueza gerada coletivamente pelos homens. Tendo como horizonte esses desafios maiores, entendendo a necessidade de transformação profunda da sociedade capitalista, o Projeto da Licenciatura em Educação do Campo é concebido a partir da interpretação que se tem sobre a função social da escola para contribuir com um desafio de tal magnitude. Para tanto, faz-se imprescindível também a transformação da própria forma escolar atual. (MOLINA, MARTINS, 2019, p. 20)

As licenciaturas em Educação do Campo é sim uma importante conquista, no entanto os professores formados nesses cursos ainda não estão presentes em grande parte dos espaços rurais brasileiros, diante desse desafio, o livro didático construído com os princípios da Educação do Campo é um importante instrumento no processo de consolidação dessa modalidade de ensino nos espaços rurais. 
Com as escolas localizadas nos espaços rurais a questão é mais complexa, pois apesar de a história do livro didático no Brasil ser longa, pouco dela está associada às características desse espaço, o livro didático sempre segue uma lógica é um discurso do urbano. E para atender à necessidade dos alunos deste espaço, foram criados programas de material didáticos específicos, no entanto é urgente estar atento a concepção de rural que está presente desses materiais, pois o projeto de educação destinada para o campo possui uma relação direta com o projeto de campo que se deseja, uma educação pautada nos princípios da educação do campo ou pautada no ruralismo pedagógico.

No Brasil, houveram alguns programas que tratavam a respeito da construção de materiais e livros didáticos para as populações do espaço rural. O Programa Escola Ativa, por exemplo, teve duração de 15 anos, tendo sido iniciado em 1997 através do Projeto Nordeste, abrangendo 12 municípios do Pará, expandindo-se a nível nacional apenas em 2009. Contudo, segundo D’Agostini, Taffarel e Júnior (2012 p.316) o Programa Escola Ativa sofreu críticas devido suas concepções de base neoliberal e por conta de "sua ineficiência para alterar os índices de qualidade da educação básica no campo", tendo seu fim no ano de 2012.

Em substituição ao Programa Escola Ativa, o movimento da Educação do Campo juntamente ao Estado, idealizaram uma extensão do Programa Nacional do Livro Didático, o Programa Nacional do Livro Didático do Campo (PNLD Campo). Essa conquista foi possível através da Portaria $\mathrm{n}^{\circ} 86$, de $1^{\circ}$ de fevereiro de 2013 que instituiu o Programa Nacional de Educação do CampoPRONACAMPO. No art. $5^{\circ}$ dessa portaria foi tratado mais especificamente sobre a construção de materiais didáticos:

Art. $5^{\circ}$ - O eixo Gestão e Práticas Pedagógicas compreende as seguintes ações: I disponibilização às escolas públicas do campo de materiais didáticos e pedagógicos que atendam às especificidades formativas das populações do campo e quilombolas, no âmbito do Programa Nacional do Livro Didático - PNLD, e de materiais complementares no âmbito do Programa Nacional Biblioteca da Escola - PNBE. (BRASIL, 2013, p.2)

Nesse sentido, o Programa Nacional do Livro Didático do Campo foi construído para atender as escolas situadas ou que mantinham turmas anexas em áreas rurais, que oferecessem os anos iniciais do ensino fundamental em turmas organizadas sob a forma multisseriada, seriada e por segmento de aprendizagem, que estivessem devidamente inscritas no censo escolar e no Programa Nacional do Livro Didático (BRASIL, 2011).

Nos editais de convocação elaborados para construção desses materiais didáticos dava-se prioridade às particularidades que envolvessem, segundo Brasil (2011, p.1) “as situações e ambientes de aprendizagem para esses públicos", devendo assim, "respeitar os critérios relativos aos aspectos legais e éticos, tais como o respeito às diferenças e a necessidade de evitar representações que estigmatizam ou propagam estereótipos". 
Em 6 anos de vigência do PNLD Campo, 3 editoras foram selecionadas para construir os materiais que traziam essas especificidades. No edital de 2011 foram selecionadas as editoras Moderna com Projeto Buriti Multidisciplinar e a editora FTD com a coleção Novo Girassol: Saberes e Fazeres do Campo, no edital de 2014 a editora FTD permaneceu com a coleção Novo Girassol: Saberes e Fazeres do Campo e a Coleção Campo Aberto da Editora Global. (SANTOS; SILVA, 2020).

Conforme trouxeram Moura e Azevedo (2018), em 2017 eram 60.770 escolas rurais no Brasil e dessas escolas 56.323 mil foram contempladas pelo programa, cerca de $92 \%$ do total existentes no país (Tabela 2). Desse modo, considera-se que houve uma abrangência consideravelmente grande alcançada por essa política e considerando que muitas vezes os professores que atuam em escolas do e no campo são advindos do espaço urbano e grande parte não possuem formação inicial e continuada que aborde os aspectos materiais e imateriais dos espaços rural, a construção, o acesso a estes LDs significou um avanço como ferramenta didática para esses docentes.

Os dados apresentados na tabela 2 possibilitam concluir que grande parte das escolas em atividade na zona rural foram atendidas pelo PNLD Campo, o que mostra a importância de políticas educacionais que levem o projeto de educação do campo para áreas onde os movimentos socioterritoriais não atuam, onde era imposto uma educação pautada em conteúdos urbanos, para muitos foi a oportunidade de ter contato com conteúdos escolares pautados na realidade do espaço e dos sujeitos dos espaços rurais.

É importante esclarecer que a tabela 2 apresenta o número total de escolas rurais em atividades por unidade da federação, mas não discrimina que nível de ensino cada escola oferece, se for escolas de educação infantil, ensino fundamental II e ensino médio, elas não podem ser atendidas pelo PNLD Campo, o mesmo ocorre com as escolas particulares. Outra informação importante é que as escolas precisam assinar um Termo de Adesão para serem inseridas no programa. Existe também uma inconsistência nos dados dos estados de Rondônia e Rio Grande do Sul, onde o número de escolas em atividades é menor do que o número de escolas beneficiadas.

Apesar de todas essas questões, os dados comprovam o alcance dessa política no espaço rural brasileiro. Entretanto, no ano de 2018, por meio do Informe $n^{\circ}$ 07/2018, do Fundo Nacional de Desenvolvimento da Educação foi anunciado o encerramento do Programa Nacional do Livro Didático do Campo. Como foi citado no anteriormente nesse artigo, através do processo de golpe e o enfraquecimento político da esquerda, os movimentos de direia e ultradireita começaram os desmanches das conquistas alcançadas pelos movimentos sociais no país. Desse modo, o encerramento do PNLD Campo representou apenas mais um caso dentre tantos outros. 
Tabela 2: Total de escolas rurais em atividades e quantidade de escolas beneficiadas pelo PNLD Campo em 2017.

\begin{tabular}{|c|c|c|}
\hline UF & $\begin{array}{l}\text { Escolas Rurais em } \\
\text { Atividade em } 2017\end{array}$ & $\begin{array}{l}\text { Escolas Beneficiadas pelo } \\
\text { PNLD Campo em } 2017\end{array}$ \\
\hline Acre & 1.181 & 1.151 \\
\hline Alagoas & 1.434 & 1.338 \\
\hline Amazonas & 3.729 & 3.638 \\
\hline Amapá & 470 & 410 \\
\hline Bahia & 982 & 8.825 \\
\hline Ceará & 3.008 & 2.581 \\
\hline Distrito Federal & 82 & 68 \\
\hline Espírito Santo & 1.111 & 1.021 \\
\hline Goiás & 529 & 477 \\
\hline Maranhão & 8.318 & 7.343 \\
\hline Minas Gerais & 3.639 & 3.488 \\
\hline Mato Grosso do Sul & 246 & 206 \\
\hline Mato Grosso & 805 & 754 \\
\hline Pará & 7.280 & 7.039 \\
\hline Paraíba & 2.234 & 2.322 \\
\hline Piauí & 2.524 & 2.506 \\
\hline Pernambuco & 3.829 & 3.789 \\
\hline Paraná & 1.332 & 939 \\
\hline Rio de Janeiro & 1.145 & 912 \\
\hline Rio Grande do Norte & 1.394 & 1.224 \\
\hline Rondônia & 492 & 503 \\
\hline Roraima & 555 & 422 \\
\hline Rio Grande do Sul & 2.116 & 2.135 \\
\hline Santa Catarina & 1.188 & 869 \\
\hline Sergipe & 988 & 983 \\
\hline São Paulo & 1.299 & 839 \\
\hline Tocantins & 560 & 541 \\
\hline
\end{tabular}

Fonte: MOURA; AZEVEDO, 2018, p. 189 e BRASIL, 2018.

Organizado por: Leonardo Santos.

Outro exemplo desse movimento que afetou e afeta a Educação do Campo mais diretamente foi a extinção da Secretaria de Educação Continuada, Alfabetização, Diversidade e Inclusão SECADI - em 2019. Segundo Taffarel e Carvalho (2019, p. 87) isso significou "medidas para destruir forças produtivas e assegurar as condições de (re)produção do capital”.

O que se percebe é que, juntamente ao desmanche dos projetos de esquerda, os movimentos oposicionistas se fortalecem através de direitos garantidos depois de tantas lutas, pois, cooptam a ideia de Educação do Campo para elaborar projetos com finalidade de formação de mão de obra especializada para agroindústria, associando a iniciativa pública e privada, como é caso do Programa Agrinho.

Pereira (2015, p.2) explica que "O "Programa Agrinho" é de responsabilidade social do sistema FAEP/SENAR/PR1, Governo estado do Paraná, prefeituras e diversas empresas e instituições parceiras" o que diminui a responsabilidade do Estado sobre a educação e passa para empresas privadas e outras organizações.

Pereira (2015, p.3) segue dizendo que "a oferta do Programa Agrinho estendeu-se para vários estados, sempre com parcerias entre o SENAR, representantes dos sindicatos patronais e instituições públicas e privadas". O autor ainda afirma que nesse modelo, a educação se integra ao mercado, pois, 
para garantia de aprovação do mesmo por parte dos envolvidos sempre são realizados concursos que tem por finalidade a premiação por desempenho dos participantes. Percebe-se além da mercantilização do ensino para os sujeitos do espaço rural, uma ruptura da ideia de trabalho coletivo para um processo de ganho individual, reforçando as ideias sobre meritocracia.

Somado a isso, surgiu no ano de 2020 um movimento organizado de mulheres ligadas ao agronegócio que se autodeclaram "mães do agro". Essas mulheres iniciaram a campanha "De olho no material escolar" que consiste em averiguar como o agronegócio está sendo tratado nas apostilas e materiais didáticos trabalhados nas escolas do país, ou seja, exigem o nivelamento dos conteúdos obedecendo à risca a Base Nacional Comum Curricular, que já é aparelhada aos interesses das elites, o objetivo é ampliar o controle do conteúdo para que não haja críticas ao modelo do agronegócio e também o controle do trabalho docente que estão sobre forte ameaça de terem suas aulas gravadas em caso de realizarem as críticas ao modelo defendido por essas mulheres. Desse modo, há um ataque, sobretudo, aos professores que atuam com as ciências humanas e sociais, pois, estes são considerados doutrinadores e difusores de ideologias de esquerda.

A partir dessas ações as instituições vinculadas ao agronegócio visam embutir nos docentes e nos educandos a ideia de que o modelo de agricultura e de vida pautado pelo agronegócio gera inúmeros benefícios para a sociedade, dificultando o processo de compreensão dos(as) jovens acerca das contradições que este modelo agrícola carrega (MOLINA, 2015).

Cabe salientar que este movimento está tomando força entre os representantes políticos da bancada ruralista no congresso e segundo a Associação de Geógrafos Brasileiros-AGB de Niterói/RJ, tem por finalidade adequar a educação brasileira sob a perspectiva do capital representado pelo agronegócio. Agronegócio este, que marginaliza os movimentos sociais agrários e, ao mesmo tempo, se favorece das conquistas políticas alcançadas pelos movimentos sociais, buscando retirar-lhes o protagonismo dessas conquistas.

Uma das principais formas de ação incentivada pela campanha "De olho material escolar" é que as mães fiscalizem os materiais utilizados nas escolas e a forma como o agronegócio é retratado neles. Sugerem que sejam feitas fotos, vídeos, ou registros quaisquer dos materiais utilizados, de forma a comprovar os problemas presentes nos materiais didáticos. [...] Todas essas ações têm sido coordenadas pela campanha "De olho no material escolar", que se organizou em Grupos de Trabalho (GT) que se dedicam a diferentes ações: (1) produção de dossiês contra materiais didáticos, a partir do envio de vídeos de "mães do agro"; (2) Frente nacional das escolas particulares, com o objetivo de pressionar a rede particular para alterar os seus materiais próprios; (3) parceria com a Sociedade Rural Brasileira (SRB) para incentivar a produção de material didático próprio e pressionar o mercado editorial; (4) parceria com professores e profissionais do agronegócio para a realização de palestras em escolas e visitas a empresas e propriedades rurais; (5) criação de uma biblioteca virtual sobre o agronegócio voltada para a formação de professores (AGB- NITERÓI; GEOAGRÁRIA, 2021, não paginado). 
Portanto, podemos observar o caráter não só conservador, mas também reacionário que permeia esse movimento. Além disso, como bem destacado pelo Grupo de Estudos, Pesquisas e Extensão em Geografia Agrária da FFP/UERJ - GeoAgrária, e pelo Grupo de Trabalho sobre Assuntos Agrários da Associação dos Geógrafos Brasileiros Seções Rio de Janeiro e Niterói GTAgrária, o próprio fato de a campanha ser direcionada unicamente às mães diz muito sobre o caráter do movimento, além de demonstrar o patriarcalismo que permeia o agronegócio brasileiro, “[...] afinal a educação dos/as filhos/as é vista como tarefa apenas das mulheres e não como uma responsabilidade conjunta de pais e mães. Além do caráter machista, podemos também destacar o racismo, uma vez que, dentre outras questões, em mais de 50 vídeos analisados não há nenhum em que apareça uma mulher ou um homem negro" (GTAGRÁRIA; GEOAGRÁRIA, 2021, não paginado).

É importante destacar que o material didático é um elemento importante, mas também é necessário ampliar a formação inicial e continuada dos professores para atuarem nas escolas rurais, os cursos de licenciaturas de educação do campo são conquistas importantes, mas também é importante que os cursos de formação professores abordem a educação nos espaços rurais e a educação do campo, pois muitos professores e professoras que atuam nessas escolas não possuem conhecimento sobre essa temática. Muitos acabaram tendo contato com a educação do campo por meio do PNLD Campo, o que foi algo positivo, mas esse desconhecimento pode ter prejudicado o uso do material.

\section{CONSIDERAÇÕES FINAIS}

A Educação do Campo, assim conceituada, existe há cerca de 23 anos e ao longo desses anos conseguiu inúmeras conquistas, bem como, enfrenta alguns desafios para manter-se ativa no cenário político e educacional do país. Muitos desses desafios surgiram e surgem devido ao viés crítico deste movimento, ao embate de classes que ele se propõe e também pela busca por uma educação emancipatória dos sujeitos do campo, desagradando uma elite que nega estes direitos à classe trabalhadora do espaço rural.

Como conquistas da Educação do Campo inclui a criação de Licenciaturas do Campo, a criação de materiais didáticos específicos para os alunos e alunas do espaço rural, a busca pela inclusão das diversidades vividas pelos diferentes sujeitos que habitam este espaço. Contudo, houve um retrocesso nessas conquistas depois do golpe político-midiático da então presidenta Dilma Rousseff e com a volta dos partidos de direita ao poder, primeiramente com a posse ilegítima do Michel Temer, depois com a chegada catastrófica do então presidente Jair Bolsonaro.

Desde então, o Brasil vivencia uma disputa acirrada entre projetos políticos, havendo por parte desses governos um desmonte, ou mesmo, a cooptação das conquistas do movimento da 
Educação do Campo obtidas depois de muito esforço coletivo, resistência e luta. Entre esses retrocessos podem ser citados: a diminuição dos repasses financeiros para manutenção dos cursos de formação docente, o encerramento do PNLD Campo, o fechamento, e em algumas vezes, até a demolição das escolas do campo.

Esse ataque à Educação do Campo deixa claro que ela representa uma ameaça ao poder do agronegócio e aos seus agentes, fato que fortalece a luta em busca de mudanças estruturais que atendam a educação e a permanência de forma adequada da população do campo no campo.

Assim, os contornos da questão agrária atual envolvem também a luta pelo direito ao acesso à educação, uma educação que seja significativa para os sujeitos do campo, que não os(as) obrigue a se deslocarem por quilômetros em veículos precários. A educação no/do campo brasileiro segue sendo esquecida, lógica esta que impacta diretamente na possibilidade de superação do analfabetismo, repercutindo um processo que há décadas fomenta a desterritorialização e a perda de cultura pelo campesinato.

A dialética permite-nos avaliar que o processo atual de fechamento das escolas e de disputa pela educação do/no campo, pode reproduzir as lutas dos movimentos socioterritoriais que foram responsáveis pelo início das reivindicações em prol do direito ao acesso à uma educação significativa em seus territórios.

\section{REFERÊNCIAS}

ALENTEJANO, P. A hegemonia do agronegócio e a reconfiguração da luta pela terra e reforma agrária no Brasil. Caderno Prudentino de Geografia, Presidente Prudente, n. 42, v. 4, p. 251-285, dez, 2020.

ALENTEJANO, P. A política agrária do governo Temer: a pá de cal na agonizante reforma agrária brasileira. Revista OKARA: Geografia em debate, v. 12, n. 2, p. 308-325, 2018.

ARROYO, M. G. Educação básica e o movimento sociais. In: ARROYO, M. G.; FERNANDES, B. M. (Orgs.). A educação básica e o movimento social do campo. 1999. p. 65-86.

BRASIL. Edital de Convocação 05/2011 - CGPLI. Programa Nacional do Livro Didático do Campo. Brasília, 2011. Disponível em: https://cchla.ufrn.br/pnld/wp-content/uploads/ 2013 edital_pnld_campo.pdf. Acesso em: 22 jun. 2021.

BRASIL. Fundo Nacional de Desenvolvimento da Educação (FNDE). Informe de Encerramento do PNLD Campo. Brasília 2018. Disponível em: https://www.fnde.gov.br/index.php/ programas/programas-do-livro/pnld/informe-pnld Acesso em: 16 jun. 2021.

CALDART, R. S. Educação do campo: notas para uma análise de percurso. In: MOLINA, M. C. (Org.). Educação do campo e pesquisa II: questões para reflexão. Brasília: MDA/MEC, 2010. p. 103-126. 
CALDART, R. S. Sobre a especificidade da Educação do Campo e os desafios do momento atual. Porto Alegre: Mimeo. 2015. 22p.

CALDART, R. S. Função social das escolas do campo e desafios educacionais do nosso tempo. Aula Inaugural do semestre do curso de Licenciatura em Educação do Campo, da Universidade Federal do Rio Grande do Sul, Campus Litoral, realizada em 9 de março de 2020. Disponível em: https://1library.org/document/zk8k8emz-funcao-social-escolas-campo-desafios-educacionais-nossotempo.html . Acesso em: 15. dez. 2020.

CAMACHO, R. S. Paradigmas em disputa na Educação do Campo. 2014. 806 f. Tese (Doutorado em Geografia) - Faculdade de Ciências e tecnologia, Universidade Estadual Paulista "Júlio de Mesquita Filho", Presidente Prudente, 2014.

CAMACHO, R. S. O PRONERA: uma política pública de educação para inclusão social da classe camponesa. Revista Mundi Sociais e Humanidades, v. 2, n. 2, p. 1-29, 2017.

CAMPOS, P. H. Os efeitos da crise econômica e da operação Lava Jato sobre a indústria da construção pesada no Brasil: falências, desnacionalização e desestruturação produtiva. Mediações: Revista de Ciências Sociais, v. 24, n. 1, p. 127-153, 2019.

D’Agostini, A.; TAFFAREL, C. Z.; JÚNIOR, C. de L. S. - Escola Ativa. In: CALDART, R. S. (Org.). Dicionário da Educação do Campo. Rio de Janeiro, São Paulo: Escola Politécnica de Saúde Joaquim Venâncio, Expressão Popular, 2012.

FERNANDES, B. M. Os campos da pesquisa em Educação do Campo: espaço e território como categorias essenciais. In: MOLINA, M. C. (Org). Educação do Campo e Pesquisa: questões para reflexão. Brasília: Ministério do Desenvolvimento Agrário, 2006. p. 27-40.

FERNANDES, B. M. Questão agrária: conflitualidade e desenvolvimento territorial. In: BUAINAIN, A. M. (Org.). Luta pela terra, reforma agrária e gestão de conflitos no Brasil. Campinas: Unicamp, 2008. p. 173-224.

FERNANDES, B. M. - A reforma agrária que o governo Lula fez e a que pode ser feita. In: SADER, E. (Org.). 10 anos de governos pós-neoliberais no Brasil: Lula e Dilma. São Paulo: Boitempo: FLACSO Brasil, 2013. p. 191-205.

FERNANDES, L. E. Ofensiva imperialista e políticas públicas anticorrupção no Brasil. Entropia, v. 3, n. 6, p. 180-199, 2019.

FRIGOTTO, G. Projeto Societário contra - hegemônico e educação do campo: desafios de conteúdo, método e forma. In: MUNARIN, A.; BELTRAME, S.; CONDE, S. F.; PEIXER, Z. I (Orgs). Educação do campo: reflexões e perspectivas. Florianópolis, 2010, p. 19-46.

GONÇALVES, R. J. de A. F.; MILANEZ, B.; WANDERLEY, L. J. Neoextrativismo LiberalConservador: a política mineral e a questão agrária no governo Temer. Revista OKARA: Geografia em debate, v. 12, n. 2, p. 348-395, 2018.

GEOAGRÁRIA - Grupo de Estudos, Pesquisas e Extensão em Geografia Agrária da FFP/UERJ: GTAGRÁRIA - Grupo de Trabalho sobre Assuntos Agrários da Associação dos Geógrafos Brasileiros - Seções Rio de Janeiro e Niterói. A nova ofensiva do agronegócio sobre a educação. Rio de Janeiro. 2021. Disponível em: https://www.agb.org.br/a-nova-ofensiva-do-agronegociosobre-a-educacao-geoagraria-e-gtagraria/. Acesso em: 13 ago. 2021. 
INSTITUTO BRASILEIRO DE GEOGRAFIA E ESTATÍSTICA (IBGE). Censo Demográfico 2010. População nos Censos Demográficos segundo as Grandes Regiões, as Unidades da Federação e a situação do domicílio - 1960/2010. Disponível em: https://www.ibge.gov.br/estatisticas /sociais/populacao/9662-censo-demografico-2010.html Acesso em: 30 mar. 2020.

INSTITUTO BRASILEIRO DE GEOGRAFIA E ESTATÍSTICA (IBGE). Pesquisa Nacional por Amostra de Domicílios. Pessoas de 5 anos ou mais de idade, por situação, sexo, alfabetização e grupos de idade. Rio de Janeiro, 2015a. Disponível em: https://sidra.ibge.gov.br/tabela /271\#resultado Acesso em: 9 ago. 2021.

INSTITUTO BRASILEIRO DE GEOGRAFIA E ESTATÍSTICA (IBGE). Pesquisa Nacional por Amostra de Domicílios. População residente, por situação do domicílio, sexo e idade, segundo a condição no domicílio e compartilhamento da responsabilidade pelo domicílio. Rio de Janeiro, 2015b. Disponível em: https://sidra.ibge.gov.br/tabela/1378\#resultado. Acesso em: 9 nov. 2020.

INSTITUTO BRASILEIRO DE GEOGRAFIA E ESTATÍSTICA (IBGE). Pesquisa Nacional por Amostra de Domicílios Contínua 2019. Informativo PNAD 2019 - Educação. 2019. Disponível em: https://biblioteca.ibge.gov.br/index.php/biblioteca-catalogo. Acesso em: 20 ago. 2020.

INSTITUTO NACIONAL DE ESTUDOS E PESQUISAS EDUCACIONAIS ANÍSIO TEIXEIRA. Sinopse Estatística da Educação Básica 2010. Brasília: Inep, 2011. Disponível em: http://portal.inep.gov.br/web/guest/sinopses-estatisticas-da-educacao-basica Acesso em: 18 jun. 2020.

INSTITUTO NACIONAL DE ESTUDOS E PESQUISAS EDUCACIONAIS ANÍSIO TEIXEIRA. - Sinopse Estatística da Educação Básica 2019. Brasília: Inep, 2020. Disponível em: http://portal.inep.gov.br/web/guest/sinopses-estatisticas-da-educacao-basica Acesso em: 18 jun. 2020.

JINKINGS, I.; DORIA, K.; CLETO, M. (Orgs.). Por que gritamos golpe?: Para entender o impeachment e a crise política no Brasil. São Paulo: Boitempo, 2016. 176p.

MARX, K. - O capital: Crítica da economia política, Livro 1- O processo de trabalho v. 1. 13. ed. Rio de Janeiro: Editora Bertand Brasil, 1989. 894p.

MITIDIERO JUNIOR, M. A.; FELICIANO, C. A. - A violência no campo brasileiro em tempos de golpe e a acumulação primitiva de capital. OKARA: Geografia em debate, v. 12, n. 2, p. 220-246, 2018.

MOLINA, M. C.; ANTUNES-ROCHA, M. I.; MARTINS. M. de F. A. A produção do conhecimento na licenciatura em Educação do Campo: desafios e possibilidades para o fortalecimento da educação do campo. Revista Brasileira de Educação, v. 24, p. 1-30, 2019.

MOLINA, M. C; MARTINS, M. F. A. Formação de Formadores: reflexões sobre as experiências da Licenciatura em Educação do Campo no Brasil. Belo Horizonte: Editora Autêntica, 2019. 432p.

MOLINA, M. C.; FREITAS, H. C. A. Avanços e desafios na construção da Educação do Campo. Em Aberto, v. 24, n. 85, p. 17-31, 2011.

MOLINA, M. C. A Educação do Campo e o enfrentamento das tendências das atuais políticas públicas. Educação em Perspectiva, v. 6, n. 2, p. 378-400, 2015. 
MOURA, F. M.; AZEVEDO, S. C. As escolas rurais, as políticas públicas e a realidade do campo. In: ENCONTRO REGIONAL DE ENSINO DE GEOGRAFIA. 6., 2018, Campinas. Anais... Campinas, 2018.

MUNARIM, A. Educação do Campo no cenário das políticas públicas na primeira década do século 21. Em Aberto, v. 24, n. 85, p. 51-63, 2011.

OLIVEIRA, A. U. Reforma Agrária, grilagem das terras públicas e a luta pela terra e território no Brasil. In: Universidad de Havana. (Org.). Por una América Latina unida y sostentable. Havana: Distribuidora nacional, 2015. p. 01-15.

PEREIRA, V. B. Concepção político-pedagógica para formação de professores do Programa Agrinho: Do campo à cidade. 2015. 148 f. Dissertação (Mestrado em Educação) - Universidade Estadual do Centro-Oeste, Guarapuava, 2015.

PEREIRA, L. I. ORIGUÉLA.; C. F. COCA, E. L. F. A política agrária no governo Bolsonaro: as contradições entre a expansão do agronegócio, o avanço da fome e o antiambientalismo. Revista NERA, v. 24, n. 58, p. 08-27, 2021.

SAMPAIO, T. V. M. Cartografia temática. Curitiba: Programa de Pós-Graduação em Geografia UFPR, 2019. 248p.

SANTOS, C. A. dos. Educação do Campo no contexto da ofensiva bolsonarista à educação brasileira. Revista da ANPEGE, v. 16, n. 29, p. 393-425, 2020a.

SANTOS, L. L. M. Territórios camponeses e o fechamento das escolas do campo: uma análise sobre a escola popular Eduardo Galeano, em Campo do Meio-MG.2020. 86 f. Monografia (Licenciatura em Geografia) - Instituto de Ciências da Natureza, Universidade Federal de Alfenas, Alfenas, 2020b.

SANTOS, A. R.; SILVA, J. F. Políticas educacionais de livros didáticos no Brasile na Colômbia: Um olhar dos estudos Pós-coloniais. Rev. Espaço do Currículo, João Pessoa, v. 13, n. 1, p. 138$152,2020$.

SAUER, S.; LEITE, A. Z. Medida Provisória 759: descaminhos da reforma agrária e legalização da grilagem de terras no Brasil. Retratos de assentamentos, v. 20, n. 1, p. 14-40, 2017.

TAFFAREL, C. N. Z.; CARVALHO, M. S. A extinção da secadi: um golpe fatal nas conquistas no campo da educação. Cadernos GPOSSHE On-line, Fortaleza, v. 2, n. 1, p. 84-90, 2019. 